\title{
RETHINKING IT GOVERNANCE FOR SMES
}

\begin{abstract}
Purpose - The purpose of this paper is to critically rethink the concepts and the theoretical foundations of IT governance in small and medium-sized enterprises (SMEs).

Design/methodology/approach - The paper is based on multiple case studies. Eight cases of outsourced information system projects where failures occurred were selected. An outsourced information system failure (OISF) is suggested as a failure of governance of the IT in a SME environment. A structure for stating propositions derived from two competing theories is proposed (Agency Theory and Theory of Trust).

Findings - The results reveal that trust is slightly more important than control issues like output-based contracts and structured controls in the governance of IT in SMEs.

Practical implications - The world of SMEs is significantly different from that of large companies, and therefore, the concept of IT governance in SMEs needs reconsideration. For researchers and practitioners, it would be more meaningful to focus on actual, working SMEs instead of on a version of their activities derived from those of large companies.

Originality/value - The paper offers two contributions. First, it elaborates the limited research on IT in SMEs and second, it brings theoretical foundations for their IT governance. The value of IT governance in SMEs is explained.
\end{abstract}

Keywords: small and medium-sized enterprise (SME), IS failures, IT governance, Agency Theory, trust, case study

Paper type: Research paper 


\section{RETHINKING IT GOVERNANCE FOR SMES}

\section{Introduction}

Small and medium-sized enterprises (SMEs) play a significant role as engines of economic and social development all over the world. Many scholars argue that a small and medium-sized enterprise cannot be seen through the lens of a large firm (Ballantine et al., 1998). Therefore, the limited theories explaining IT (Information Technology) governance in large organizations cannot be linearly extrapolated to SMEs, since we are dealing with a completely different economic, cultural and managerial environment. Notwithstanding the efforts to develop guidelines for governing IT in SMEs, such as the Cobit QuickStart method, the results of applying these frameworks in SMEs are rather disappointing (IT Governance Institute, 2007). Scholars and practitioners are too grounded in their way of thinking, and maintain a simple vision of a SME as a scale model of a large firm (Raymond, 1985). There is also a lack of genuine SME-centred theories that can lead to general inferences about how SMEs should govern their IT. Riemenschneider et al. stated that, "...organizational theories and practices, such as bureaucratic structure and organizational behaviour applicable to large organizations, may not be valid in small ones" (Riemenschneider et al., 2003: 269).

SMEs seldom have a dedicated IT staff or a well-defined and formal IS (Information Systems) function (Adam and O'Doherty, 2000). Due to their small scale, and hence a lack of in house IT skills, SMEs depend more on IT vendors than large companies (Thong, 2001; Thong et al., 1997). However, outsourcing is not without risks or problems. From a managerial point of view, we associate risk in IT outsourcing with negative outcomes. One risk scenario that is of special interest for this research is the occurrence of IS failures. IS failures can lead to disputes, which can be classified as litigation and non-litigation. The focus of this work is the constructs of trust and control in relation to outsourced IS projects in SME environments. This paper is based upon on-going research on IT governance in SMEs and reports on some recent findings based on a positivistic research strategy of multiple case studies, as well as on investigation of IS failures in an outsourced SME environment.

In the following sections, we first provide overviews of the specific relationships between SMEs and IT, outsourced IS failures and IT governance. We elaborate on the theoretical foundations of trust and control in the fourth section. The fifth section details the research methodology and design, and includes the results of our testing of the propositions by the multiple case studies, our empirical observations, and a discussion of our findings. Finally, our conclusions are stated in the sixth section, including the implications of our findings for future research and practice.

\section{SMEs and IT}

Research and literature have highlighted the problems of defining SMEs. Companies differ in size, location, ownership structure, financial performance, maturity, and management style. It would be ideal to clearly define a SME before starting any research on them, but this is not straightforward. There are many characteristics that identify a SME besides size. The European Commission took an initiative to define a SME in terms of microeconomic characteristics such as turnover (not exceeding 50 million euro), annual balance sheet total (not exceeding 43 million euro) and headcount (fewer than 250 persons) (Commission 2003).

In this research, we focus on SMEs with a headcount less than 200 employees, family-owned businesses that are managed by family members, with a turnover less than $€ 20$ million, mainly operating in a domestic market and having no IT department. Although this group of SMEs is still very heterogeneous, many similarities in implementing an IT project can be observed for this group. 
Existing research on IT and SMEs is fragmented in terms of findings and conceptual approaches (Harrison et al., 1997; Premkumar, 2003). However, we focus here on two major findings: the role of the CEO as the principal decision maker in SMEs (Cragg, 2008; Lefebvre et al., 1997; Thong et al., 1997), and the dependency of SMEs on external IT expertise (Thong, 2001; Thong et al., 1997). Thong has shown that both findings are related. "The results show that the most effective IS implementation environment is one in which both top management support and external IS experts work as a team" (Thong, 1997: 253). CEO-centric decision making suggests that SMEs require less bureaucratic methods of management and greater flexibility, with a strong focus on people and less focus on process orientation. SMEs still tend to be too much taskoriented, leaving almost no space for the adaptation of cross-functional capabilities into rigid business processes (Antlova, 2009; Chang et al., 2010). The need for external expertise suggests a staff with a lack of specialization and a lack of people able to undertake a wide range of duties. The smaller the business, the less it is able to hire people with specialized skills, for example, IT skills (Alpar and Reeves, 1990). The shortage of internal IT capabilities and techniques is the major reason why SMEs tend to outsource IT, and consequently, depend heavily on external IT expertise. Here we take a snapshot of organizations that have outsourced their IS function almost completely, a decision often made in SMEs out of necessity.

\section{Outsourced IS failures}

Despite the numerous success stories illustrating the advantages of bringing IT into organizations, it is widely accepted that the processes of designing, developing and implementing IT are cumbersome and not straightforward. Both recent and previous reports show that IS projects frequently fail. Broad and elaborate research on IS failures has been conducted for more than four decennia (Avison et al., 2006; Ewusi-Mensah, 2003; Iacovou and Dexter, 2005; Lyytinen and Hirschheim, 1987; Sauer, 1993). Practitioners and expert witnesses frequently report IS failures in SMEs as well as in large companies (Standish Group, 2004).

IS failures can be divided into expectation (Lyytinen and Hirschheim, 1987) and termination (Sauer, 1993) failures. Expectation failures can be further categorized into correspondence, process and interaction failures. Correspondence failures occur when information systems are evaluated in terms of previously defined design objectives. A lack of correspondence between design objectives and evaluation is seen as a failure. Process failures occur when there is unsatisfactory development performance, i.e., failure to produce a workable system or to deliver within the budget constraints of time and costs. Process failures are sometimes called 'runaways' or escalating projects (Iacovou and Dexter, 2005). Interaction failures represent the mismatch between requirements and user acceptance. An interaction failure appears when an information system is not used. In summary, an expectation failure is the inability of an information system to meet the expectations of the stakeholders.

Sauer introduced a more pragmatic concept of the termination failure (Sauer, 1993). According to Sauer, an IS failure only occurs when the development process or the operation of an information system causes dissatisfied stakeholders to abandon the project.

We argue that there is an extra dimension to IS failures that is not fully explained covered by those descriptive models, which we call the outsourced IS Failure (OISF). An OISF is a failure that occurs during an IS project in an outsourced environment. We use the taxonomy of outsourcing options of Lacity and Hirschheim (Dibbern et al., 2004) and we focus on project management. Some academics have already pointed out that outsourcing increases the risks that lead to IS failures (Aubert et al., 2003; Bahli and Rivard, 2003; Natovich, 2003). In our work, we focus on IS project failure factors, not from a risk perspective but from real instances of failed projects. However we used a list of possible failure factors based on the validated list of risk factors edited by Schmidt et al. to examine our cases and added extra outsourcing risk factors based on the work of Aubert et al. and Natovitch (Schmidt et al., 2001; Aubert et al., 2005; Natovich, 2003). 


\section{IT governance}

IT governance is a term that has been evolving rapidly over the last few years, especially in practitioners' communities. The IT Governance Institute is taking a leading role in the debate. Many aspects of IT governance have been described and detailed but little work has been done to pull it all together. From an academic perspective, research on IT governance is emerging as an important area of enquiry (Bernroider, 2008; Huang et al., 2010; Schwarz and Hirschheim, 2003; Weill and Ross, 2005).

The vital role of IT in enterprises has led to the view that IT governance must be implemented to sustain and enable business objectives and to mitigate associated risks. IT governance directly influences the benefits generated by organizational IT investments (Weill and Ross, 2004). This holds true for large as well as for small businesses. However, the mechanisms of IT governance are applied much more extensively in large enterprises than in SMEs (Huang et al., 2010). Existing mechanisms of IT governance, such as the way critical IT processes are conducted, the creation of management guidelines to accompany these IT processes, and the assignment of responsibilities and accountability seem to fail in SMEs, where decision making is mostly centred round one person (Levy and Powell, 2008). The concept of IT governance originates from the discussion of strategic IT planning and IT management, but its link to an overall corporate governance structure is 'a bridge too far' for most SMEs. This calls for a rethinking of the concept of IT governance when applied in SMEs.

We see an outsourced information system failure (OSIF) as a failure of governing IT in a SME environment and we propose a new structure for IT governance in SMEs, stating propositions derived from both Agency Theory and the Theory of Trust. How and why OISFs occur in SMEs are the theoretical questions addressed in this paper. An overview of the literature provides strong support for the belief that the constructs of trust and control are both of significant importance. Mohtashami et al. stated that, “... The absence of a proper level of trust is the primary reason for a large percentage ( 40 to 70 percent) of collaboration failure ..." (Mohtashami et al., 2006: 27).

\section{Research design}

To explain OISF and the failure of IT governance in SMEs, we draw on Agency Theory and on the Theory of Institutional Trust in order to construct testable propositions. We consider both theories as process theories (Markus and Robey, 1988; Soh and Markus, 1995) as well as rival or competing theories. Both theories have discrete outcomes that may not occur, even when qualifying conditions are present, and have a logical form in which conditions are expressed as qualifications that are necessary or sufficient, rather than as dependent and independent variables. Time is also a crucial factor for both theories, since these conditions are built up during the course of an IT project. Both theories can be considered as falsifiable, with the potential of deducing logical and consistent propositions (Lee, 1989). We also construct rival propositions from the theories. The theories all have at least some explaining power. We follow the same logic to induce propositions such as Sarker and Lee (Sarker and Lee, 2003). First, we elaborate on the two theories.

\section{Trust}

The concept of trust is subtle, diffuse and elusive. Although there is agreement on the importance of trust, there also appears to be disagreement on a suitable definition of the construct (Bigley and Pearce, 1998). Trust can be seen as a coordinating mechanism, based on shared moral values and norms, and supporting collective co-operation and collaboration within uncertain environments (Reed, 2001). Blois gives a number of definitions of trust that are frequently quoted in papers (Blois, 1999). Trust/control relationships between organizations can be seen as highly complex structures of social relations and as processes that are needed for the generation and maintenance of collective action. The concept of trust is crucial in business interactions that are characterized by mutual dependency, combined with a lack of mutual control. Some researchers argue that trust is also reciprocal. According to Reed, “... the essential character of all trust relations is their reciprocal 
nature. Trust tends to evoke trust, distrust to evoke distrust ... As trust shrinks, distrust takes over ..." (Reed, 2001: 203). Gefen gives a working definition of trust that is already used in IS research and is the most suitable for our empirical setting. "Trust is the belief that others upon whom one depends, yet has little control over, will not take advantage of the situation by behaving in an opportunistic manner, but rather, will fulfil their expected commitments by behaving ethically, dependably and fairly, especially under conditions involving risk and potential loss" (Gefen, 2004: 264).

Trust can occur on a personal level or on an organizational level. The latter is also known as institutionalized trust. The concept of personal trust appears to be more relevant in family-owned SMEs, where the central role of the CEO has been identified as a key factor for effective IS implementation. However, Zaheer et al. found that interpersonal and organizational trust are highly correlated (Zaheer et al., 1998).

Sabherwal states that inter-organizational relationships involve a psychological contract and a formal written contract. The written contract is negotiated and well understood, while the psychological contract consists of unwritten and largely unspoken sets of expectations held by the transacting parties about each others' prerogatives and obligations (Sabherwal, 1999). Governing IT in an outsourced environment requires dealing with both types of contracts. Trust supports the psychological contract. An outsourced IT project in a SME environment can be seen as an interpersonal cooperation and exchange. Trust limits the need for structured controls by reducing the perceived need to guard against opportunistic behaviour when unexpected changes occur in an IT project. Structural controls are appropriate mechanisms and include deliverables, reporting arrangements, meeting schedules, and penalty clauses to govern the project and to address compliance with the contract (Sabherwal, 1999). Trust can also be seen as a mechanism for reducing complexity. Trust does not contribute to the complexity, but tries to avoid or to reduce it. Theoretically, the role of trust in an outsourced IS environment appears to be an important one.

The concept of trust has already been used in IS research (Gefen, 2004; Lander et al., 2004; Mohtashami et al., 2006; Sabherwal, 1999) and in related environments, such as R\&D (Blomqvist et al., 2005), and also in the study of business-to-business relationships (Blois ,1999).

\section{Control}

A predominant theory, central to western management thinking and one of the cornerstones for governance, is the Agency Theory (Eisenhardt, 1989b; Jensen and Meckling, 1976). The Agency Theory has its roots in the research of decision making and is used as an explanation of the theory of the firm. Its original setting cast the principal as the firm's owner(s) and the agent as the manager(s). Agency Theory and derivative theories, such as Control Theory and IT Governance are also very popular theories used in IS research (Aubert et al., 2005; Choudhury and Sabherwal, 2003; Weill and Ross, 2004). Together with Transaction Cost Economy Theory, Agency Theory is seen as the foundation of IS outsourcing (Dibbern et al., 2004). However, its contribution has not always been made clear, since the excessive truth-claims and assumptions of Agency Theory are based entirely on analyses in environments other than IT/IS.

Agency Theory views the problems that occur in outsourced environments as the results of three factors: goal differences, differences in risk behaviour and asymmetry of information. It assumes that the agent vendor has private information about the quality of the IS that is not available to the principal (SME). According to Agency Theory, agents can therefore act in their own best interest and exhibit opportunistic behaviour, which can lead to moral hazard. However, when the principal and the agent are making contracts, the negotiated transaction can never be described perfectly. Anderlini and Felli state that, “... the contracting parties may lack the necessary degree of rationality to accurately (the ability, the time, the language or the computational resources) necessary to describe the various states of nature in the ex-ante contract they draw up ..." (Anderlini and Felli, 2004: 5).

The complex balancing relationship between trust and control is elaborated by Reed (Reed, 2001). Although this relationship can be seen as a nexus, there is also rivalry in the theoretical underpinnings. However, this rivalry can be considered to be commingled rivalry (Yin, 2003). 


\section{Derived propositions}

According to Agency Theory, opportunistic behaviour is corrected by control. Kirsch views control as encompassing all attempts to ensure that individuals in organizations act in a manner that is consistent with meeting its organizational goals and objectives (Kirsch, 1997). There are several ways to deploy control. Here, we consider the creation of an outcome-based contract and on the implementation of structured controls to obtain compliance with the contract mechanisms used to deploy control. An outcome-based contract offers the best solution in a setting where there is asymmetry of information (Grossman and Hart, 1983). We came to the following three propositions, induced from Agency Theory.

\section{P1. An OISF must happen if there are no structured controls implemented.}

Proposition P1 implies that the absence of implemented, structured controls is a sufficient but not necessary condition for an OISF. This also implies that if there are no structured controls implemented, and there is no OISF, the proposition is falsified. Structural controls can be seen as the mechanisms of IT governance and examples are steering committees, management guidelines, policies and procedures.

\section{P2. An OISF must happen if the contract is not outcome-based.}

Proposition P2 implies that the absence of an outcome-based contract is a sufficient, but not necessary condition for an OISF. This also implies that if there is no outcome-based contract and there is no OISF, the proposition is falsified. In extremis, an outcome-based contract is a no-cure-no-pay contract.

\section{P3. An OISF must happen if there are no structured controls implemented and the contract is not outcome-based.}

Proposition P3 implies that in an outcome-based contract, together with (logically 'and'), the absence of implemented structured controls is a sufficient, but not necessary condition for an OISF. This also implies that if the combined condition is true and there is no OISF, the proposition is falsified. Proposition P3 is much stronger than P1 and P2 separately, since both conditions (outcome-based contract and structured controls) must appear simultaneously.

We also induced a proposition from Institutional Trust Theory. The operationalization of the construct of trust is based on the work of Lander and Sabherwal, who divided trust into three types: calculus-based, knowledgebased and identification-based trust (Sabherwal, 1999; Lander et al., 2004).

Calculus-based or deterrence-based trust is the lowest form of trust and exists when both parties can be trusted to keep their word. The deterrence is rooted in the rewards and punishments of the project and can be found in the project contract. Knowledge-based trust is based on the predictability of the other party, developed though knowing the other sufficiently well that their behaviour is predictable. The highest order of trust is identification-based trust and is developed when one party has fully internalized the other's wants, and this mutual understanding is developed to the point that each can effectively act for the other (Lander et al., 2004). These authors also developed a list with trust-building mechanisms for each level of trust. Based on the characteristic that trust has a reciprocal nature, we looked for distrust-evoking events and for trust-building mechanisms in our observations.

We came to the following proposition.

\section{P4. An OISF must happen if there is no trust between the principal (SME CEO) and the agent.}

Proposition P4 implies that the absence of trust (or distrust) between both parties in the exchange is a sufficient, but not necessary condition for an OISF. This also implies that if there is trust between the principal and the agent and there is an OISF, the proposition is falsified. 


\section{Research methodology}

In this research, a qualitative analysis of multiple SME cases was undertaken. The cases are presented in Table 1. The choice for qualitative research is based on the accessibility of well-documented, secondary data in the litigation files of failed IS projects in SMEs. Eight cases of IS projects were selected. We used the concept of a termination error to define a failed project (Sauer, 1993).

OISFs are embedded in an organizational context that is not separable from the unit of analysis. There are definitely more variables to be studied than there is available data. This is a situation where the case study is an ideal research strategy (Lee, 1989; Yin, 2003). According to Yin, case study research is useful when a phenomenon cannot be studied outside the context in which it occurs or where the boundaries between phenomenon and context are not clearly evident. Sauer shares the opinion that research of IS failures is best done by case study (Sauer, 1993; Yin, 2003). The development of the research design and methodology was inspired by the work of researchers experienced in case study research (Dube and Pare, 2003; Eisenhardt, 1989a; Lee, 1989).

\begin{tabular}{|l|l|l|l|l|l|l|l|}
\hline $\begin{array}{l}\text { Case } \\
\text { Name }\end{array}$ & Sector & $\begin{array}{l}\text { Turnover } \\
(\text { million })\end{array}$ & Staff & $\begin{array}{l}\text { Type of } \\
\text { Project }\end{array}$ & $\begin{array}{l}\text { Cost of } \\
\text { Project }\end{array}$ & Result & $\begin{array}{l}\text { Dispute } \\
\text { Resolution }\end{array}$ \\
\hline Rockit & Textile & $€ 11.64$ & 67 & ERP $^{1}$ & $€ 644000$ & No failure & - \\
\hline Woody & Trading & n.a. & $<200$ & SDI $^{2}$ & $€ 372000$ & $\begin{array}{l}\text { Process } \\
\text { failure }\end{array}$ & Litigation \\
\hline Mach & Manufacturing & $€ 12.75$ & 146 & ERP & $€ 90000$ & $\begin{array}{l}\text { Expectation } \\
\text { failure }\end{array}$ & Litigation \\
\hline Bupo & Software & $€ 0.475$ & 8 & SD $^{3}$ & $€ 50000$ & $\begin{array}{l}\text { Process } \\
\text { failure }\end{array}$ & Litigation \\
\hline Dybo & Trading & $€ 15.65$ & 16 & SDI & $€ 50000$ & $\begin{array}{l}\text { Process } \\
\text { failure }\end{array}$ & Litigation \\
\hline Stones & Manufacturing & $€ 31.25$ & 200 & ERP & $€ 750000$ & $\begin{array}{l}\text { Expectation } \\
\text { failure }\end{array}$ & ADR \\
\hline Boxcars & Service & $\begin{array}{l}€ 5.00- \\
€ 20.00\end{array}$ & $10-30$ & DIS & $\begin{array}{l}60 \mathrm{x} \\
€ 75000\end{array}$ & $\begin{array}{l}\text { Expectation } \\
\text { failure }\end{array}$ & ADR \\
\hline Hero & Service & $€ 4.00$ & 5 & SDI & $€ 75000$ & $\begin{array}{l}\text { Escalation } \\
\text { failure }\end{array}$ & Litigation \\
\hline
\end{tabular}

${ }^{1}$ ERP $=$ Enterprise Resource Planning

${ }^{2} \mathrm{SDI}=$ Software Development and Implementation

${ }^{3} \mathrm{SD}=$ Software Development

${ }_{5}^{4} \mathrm{DIS}=$ Dealer Information System

${ }^{5} \mathrm{ADR}=$ Alternative Dispute Resolution

Table 1. The selected cases

The unit of analysis in all cases was an IS project in an SME environment that was subject to an OISF. Since this was a multiple-case study, we followed replication logic to offer external validity. 'Generalizability' is of major concern in all research, but in this kind of work, it cannot be statistical. The kind of generalization that was established was an analytical generalization or a generalization from case study findings to theory (Lee and Baskerville, 2003; Yin, 2003). The theoretical generalization from the empirical description in our case study has no value beyond the given cases. However, the generalization from ideographic details to theory is important for the clarification of theoretical concepts. Therefore, the cases were chosen carefully, in order to accomplish literal replication logic (seven cases), as well as theoretical replication logic (one case). In each 
case, there was at least some initial evidence of incomplete and asymmetric information, hidden actions and hidden intentions on behalf of the agent.

We used a longitudinal approach in all cases. Three sources of evidence were used to ensure construct validity: 1) documents, 2) focus and open-ended interviews, and 3) direct and participant observations. Project documentation, minutes from steering committee meetings, memoranda and letters were analysed. Documents were delivered by three sources: plaintiff, defendant, and expert witness. The documents of the plaintiff and defendant were often the same, but were brought into litigation because of opposing opinions. All reports of expert witnesses were exposed through cross-examination of all parties and were corrected if material errors occurred. This resulted in an extra triangulation of the available data. The interviews were recorded on audiotapes, written down in reports, and sent to all parties for cross-examination. All interviews took place in the presence of all parties and the expert witness. The sites of the case studies were visited at least four times for the purpose of doing interviews and making direct observations. The data coming from all sources were coded by means of a coding scheme, which is part of the protocol of the case study. The coding scheme separates the basic data from the metadata (the documents, reports and sheets) and was designed to avoid data contamination. All data were stored in a computerized case study database and links were made between basic data and metadata. The data are retrievable by computer but are also available in original and raw format for reviewers.

Data were analysed in two steps. The first step was a 'within-case analysis' to review the unique patterns of each case. Second, a 'cross-case analysis' was conducted in search of common patterns. The cases were selected to allow comparison and to maximize variation, while respecting the ceteris paribus criteria, so that our multiple case study is analogous with multiple experiments as shown in Table 1.

Similarities pertain to the size of the enterprises; all principal sites are family-owned SMEs, and there is a strategic importance for the IS project. In terms of variation, three projects are ERP implementations, three projects are software development and implementation projects (SDI), and one project is a software development project without implementation (SD). Customizing took place for all ERP projects. Two cases (Stones and Boxcars) were subject to alternative dispute resolution (ADR).

Table 2 gives an overview of the observations in our research. For each case, we looked at:

- Type of contract: outcome-based and behaviour-based. In some cases, a mixed type was discovered in which some parts of the contact were outcome-based (in particular software licenses) and others (in particular, consultancy fees) were behaviour-based;

- Structural controls: appropriate mechanisms including deliverables, reporting arrangements, meeting schedules, and penalty clauses for governing the project. We searched for two aspects of structural controls: those stipulated in the contract and those applied during the course of the project;

- Information asymmetry: traces of private information at both parties;

- Hidden actions: traces of hidden actions of principle and agent;

- Lack of commitment, including the lack of oversight and engagement by executives;

- Well defined user requirements;

- Level of trust: deterrence-based or calculus-based, knowledge-based and identification-based;

- Distrust evocation: broken promises, lies and personnel changes in the project team;

- Trust deterioration or decline of trust: parties reacting with formal writing;

- Trust-building mechanisms: integrity (fulfilling promises, telling the truth), predictability (consistency, clear roles with responsibilities and accountabilities), communications (openness, receptivity, creating common language), and commitment and sharing of control. 


\begin{tabular}{|c|c|c|c|c|}
\hline Observation & Case Rockit & Case Woody & Case Mach & Case Bupo \\
\hline IT maturity & $\mathrm{CMM}^{1}$ level 1 & CMM level 1 & CMM level 1 & CMM level 1 \\
\hline Type of contract & Behaviour-based & Outcome-based & Mixed & Outcome-based \\
\hline $\begin{array}{l}\text { Structural controls in } \\
\text { contract / in project }\end{array}$ & Yes/No & Yes/Yes & Yes/No & Yes/No \\
\hline Private information (agent) & Yes & Yes & Yes & Yes \\
\hline $\begin{array}{l}\text { Private information } \\
\text { (principal) }\end{array}$ & Yes & No & Yes & No \\
\hline Hidden actions agent & No & Yes & Yes & Yes \\
\hline Hidden actions principal & No & No & Yes & No \\
\hline Lack of commitment (agent) & No & Yes & Yes & Yes \\
\hline $\begin{array}{l}\text { Lack of commitment } \\
\text { (principal) }\end{array}$ & No & No & No & No \\
\hline Well defined requirements & No & Yes & No & Yes \\
\hline Level of trust & Identification & Deterrence & Deterrence & Deterrence \\
\hline Distrust evocation & No & Yes & Yes & Yes \\
\hline Trust deterioration & No & Yes & Yes & Yes \\
\hline Trust-building mechanisms & Yes & No & No & No \\
\hline Observation & Case Dybo & Case Stones & Case Boxcars & Case Hero \\
\hline IT maturity & CMM level 0 & CMM Level 2 & CMM level 1 & CMM level 0 \\
\hline Type of contract & Mixed & Behaviour-based & Mixed & Outcome-based \\
\hline $\begin{array}{l}\text { Structural controls in } \\
\text { contract / in project }\end{array}$ & No/No & Yes/Yes & Yes/Yes & Yes/No \\
\hline Private information (agent) & Yes & Yes & Yes & Yes \\
\hline $\begin{array}{l}\text { Private information } \\
\text { (principal) }\end{array}$ & No & No & No & Yes \\
\hline Hidden actions agent & No & Yes & Yes & No \\
\hline Hidden actions principal & No & No & No & No \\
\hline Lack of commitment (agent) & No & No & No & No \\
\hline $\begin{array}{l}\text { Lack of commitment } \\
\text { (principal) }\end{array}$ & Yes & No & Yes & Yes \\
\hline Well defined requirements & Yes & Yes & Yes & No \\
\hline Level of trust & Deterrence & Knowledge & Deterrence & Deterrence \\
\hline Distrust evocation & Yes & Yes & Yes & Yes \\
\hline Trust deterioration & Yes & No & No & Yes \\
\hline Trust-building mechanisms & No & No & No & No \\
\hline
\end{tabular}

\section{$1 \mathrm{CMM}=$ Capability Maturity Model}

Level 0: Complete lack of any recognisable IT processes. The enterprise had not even recognised that there is an issue to be addressed.

Level 1: Initial level. There is evidence that the enterprise has recognised that IT issues exist and need to be addresses. However there are no standardised processes and the management approach is ad hoc.

Level 2: Repeatable level. The IT processes have developed to the stage where similar procedures are followed by different people undertaking the same task. There is however no formal training and responsibility is left to the individual.

Table 2. Overview and summary of case observations 


\section{Results}

We have summarized the major observations of trust, information asymmetry and hidden actions in Table 3 and structural controls, trust and type of contract in Table 4. Table 4 is also the presentation of the logic behind the falsification of the propositions.

\begin{tabular}{|c|c|c|c|c|c|}
\hline Case & OISF & Trust & $\begin{array}{c}\text { Information } \\
\text { Asymmetry }\end{array}$ & $\begin{array}{c}\text { Hidden } \\
\text { Actions } \\
\text { Agent }\end{array}$ & $\begin{array}{c}\text { Hidden } \\
\text { Actions } \\
\text { Principal }\end{array}$ \\
\hline Rockit & No & Yes & Yes & No & No \\
\hline Woody & Yes & No & Yes & Yes & No \\
\hline Mach & Yes & No & Yes & Yes & Yes \\
\hline Bupo & Yes & No & Yes & Yes & No \\
\hline Dybo & Yes & No & Yes & No & No \\
\hline Stones & No & Yes & Yes & Yes & No \\
\hline Boxcars & No & Yes & Yes & Yes & No \\
\hline Hero & Yes & No & Yes & No & No \\
\hline
\end{tabular}

Table 3. Summary of the findings: Information Asymmetry and Hidden Actions

First, the observations in Table 3 indicate that Agency Theory certainly has the power to predict opportunistic behaviour in situations where information asymmetry is at play. In all cases, information asymmetry could be observed and in five cases (Woody, Mach, Bupo, Stones and Boxcars) this led to hidden actions of the agent. However, in one case (case Mach), hidden actions on behalf of the principal could also be observed. This is a finding that was already suggested by Moynihan. "Agency Theory views the exchange primarily from the perspective of the principal. But what of the agent's perspective? What strategies can agents use to protect themselves from potentially opportunistic or other unfavourable forms of behaviour on the part of the principal" (Moynihan, 2002: 378)? Aubert et al. report similar findings: "Both clients and vendors tend to behave opportunistically when entering into a contract and this can lead to mutual disadvantage" (Aubert et al.,2003: 183).

Hidden actions on behalf of the agent, once revealed, led to a withdrawal of trust by the principal in three relevant cases (Woody, Mach and Bupo). However, for the cases Dybo and Hero, there was a deterioration of trust but no hidden action on behalf of the agent could be observed.; the agent was playing with open cards, no hidden actions could be observed and no evocation of distrust occurred.

In Table 4, we can observe the competing theoretical constructs and the derived propositions.

\begin{tabular}{|c|c|c|c|c|c|c|c|c|}
\hline Case & OISF & Trust & $\begin{array}{c}\text { Structured } \\
\text { Controls }\end{array}$ & $\begin{array}{c}\text { Outcome- } \\
\text { based } \\
\text { contract }\end{array}$ & P1 & P2 & P3 & P4 \\
\hline Rockit & No & Yes & No & No & No & No & No & No \\
\hline Woody & Yes & No & Yes & Yes & No & No & No & Yes \\
\hline Mach & Yes & No & No & Yes & Yes & No & No & Yes \\
\hline Bupo & Yes & No & No & Yes & Yes & No & No & Yes \\
\hline Dybo & Yes & No & No & No & Yes & Yes & Yes & Yes \\
\hline Stones & No & Yes & Yes & No & No & No & No & No \\
\hline Boxcars & No & Yes & Yes & No & No & No & No & No \\
\hline Hero & Yes & No & No & Yes & Yes & No & No & Yes \\
\hline
\end{tabular}

Table 4. Summary of the findings: falsification of the propositions. 
Light shadowing (green) indicates a confirmation of the proposition.

Dark shadowing (red) indicates a falsification of the proposition

The falsification of proposition P1 is carried out by comparing the column 'Structured Controls' with the column 'OISF'. There are five OISFs (Woody, Mach, Bupo, Dybo and Hero) and there are five cases with no structured controls (Rockit, Mach, Bupo, Dybo and Hero). Only the cases Mach, Bupo, Dybo and Hero match all of the findings of proposition P1. These cases are highlighted in green in the column P1. In these four cases, no structured controls were applied and the OISF took place. However, in case Rockit, we could also observe an absence of structural controls, although no OISF occurred. The case Rockit is highlighted in red in the column P1.This led to the conclusion that proposition P1 is falsified. OISFs do not always happen if there are no structured controls.

Concerning proposition P2, and following the same logic, but now for the construct 'Outcome-based contract', only case Dybo followed a pattern that matched with proposition P2. There was no outcome-based contract but an OSIF occurred in this case. However, the cases Stones and Boxcars also had no outcome-based contracts and an OISF did not occur. These parties went to alternative dispute resolution. The CEOs sat around the table to work on a solution to save the project and to save a future collaboration. An emerging OISF, which was already ripe to bring into litigation, was avoided. In case Rockit, there was no outcome-based contract and no OISF occurred. This led to the conclusion that proposition P2 is falsified.

The most compelling evidence can be found for proposition P3, in which only cases Dybo and Rockit showed a relevant match with the conditions. Structured controls were not applied and there was no outcome-based contract. Case Dybo went into litigation with an OSIF; however, in case Rockit, there was no OISF, leading to the conclusion that proposition P3 is falsified.

Finally, all relevant empirical patterns in the cases matched with proposition P4. An OSIF must happen if there is no trust between the principal and the agent.

\section{Discussion}

We can conclude that trust is presumably more important than output-based contracts for eliminating opportunistic behaviour in family-owned SMEs. Even with structural controls in place, trust is necessary to prevent failure. Trust also seems to be more important than structural controls for eliminating opportunistic behaviour in SMEs. The propositions, deduced from Agency Theory, are theoretical but not empirically logical. The world of family-owned SMEs is significantly different from that of large companies. Although we did not find any evidence that the same findings may also hold true for non-SMEs, we believe that the specific management structure in family-owned SMEs, centred round the CEO as the main decision-maker, is truly a discriminating factor.

There is another intriguing finding. In all cases, except case Rockit, we could observe evocation of distrust on behalf of the agent. In these cases, we could observe that sales representatives of the agent organization made promises in the tendering phase of the project that could not be fulfilled once the project had started. The fact that those promises were accepted is probably due to the lack of power of observation of the principal, ex ante. Although these promises often touched the essentials of an outsourced IS project, on commitments such as price, budget and quality (functionality), agents made them in vain and therefore jeopardized the success of the outsourced IS project. Ex post, when the contract was signed and the endeavour with the agent actually began, the agent did not keep his promises, which evoked mistrust with the principal very early in the project trajectory, and this could not always be mended during the course of the project, due to a lack of trust-building mechanisms. These observations were predicted by Agency Theory and the false promises led to an adverse selection by the principal. This is a most interesting topic, which needs further investigation.

We cannot conclude that structural controls are pointless in SME environments. However, it can be seen as a serious warning to independent software vendors to take care when they step into an IS project with a SME. 
They should be aware that SMEs often lack the necessary skills to conduct an IS project with the proper structured controls. When controls fail, trust should take over.

This could also indicate that trust and control are not necessarily rival theories. As Reed stated, "In short, the conventional dichotomy between normatively-based trust and politically-based control has become unsustainable, as the theoretical and empirical work in organizational analysis has consistently blurred the putative analytical and substantive boundaries between them" (Reed, 2001: 202).

The findings that trust is an important construct between collaborating partners raise some important considerations on how to deal with trust from a managerial perspective. First, the issue of deterioration of trust is a major concern for the agent. Although trust has a reciprocal nature, it is the agent who has to work hardest on trust-building mechanisms in order to maintain or to increase the level of trust. Devos et al. found that there is always incentive for adverse selection and moral hazard as long as the SME-principal is not willing to pay the costs required to avoid the asymmetry of information (Devos et al., 2010). The market where SMEs buy IT is attractive for small independent software vendors (ISV) acting as business partners of top-notch ERP suppliers and IS/IT suppliers. However, the capability and maturity level of the ISVs is often inadequate to match the demands and complex challenges of an IS implementation in a SME environment. A situation of severe asymmetry of information occurs because SMEs are not well informed about the correct IT/IS capabilities of the ISVs, the broad functionalities of the software package and the efforts needed to adapt the software to their specific requirements. The findings indicate that this almost always leads to opportunistic or even unethical behaviour on behalf of the ISV.

\section{Conclusions}

It has always been assumed that IT governance is achieved through control of IT, with Control Theory acting as a sole basis for conceptualizing IT governance. Consequently, practitioners adopt the Control Theory stance in operationalizing IT governance. However, caution is needed in applying the mechanisms of IT governance in an SME environment (Institute 2007). We argue that in a SME environment, social-psychological processes with constructs like trust (and probably also fairness, intuition and empathy) are of more importance in explaining the complex IT governance phenomena than are Agency Theory and (formal) Control Theory, and are therefore, more appropriate for deriving guidelines for practitioners. Our findings clearly show that the role of governance is different in SMEs than in large companies. SMEs require simple and informal control systems with adequate reporting and a higher focus on people. The CEO is the crucial stakeholder of an IS project in a SME, and very often, this CEO lacks commitment, time and knowledge. This suggests an important unit of analysis for future empirical research. The authors argue that practitioners as well as researchers should incorporate a more idiosyncratic profile of SMEs in their way of thinking when dealing with SMEs and IT governance.

OISFs in SMEs appear to occur due to a lack of trust of the principal in the actions of the agent during an IS project. Our findings indicate that SMEs tend to lean more on trust and trust building in a collaborative project than on structured controls. It is remarkable that the level of trust is also important. Deterrence-based trust is not enough to be considered as an inhibitor for an OISF. Deterrence-based trust can be seen as a structured control since it is rooted in the rewards and punishments associated with a particular project and incorporated in the written contract (Sabherwal, 1999). Only the more developed levels of trust prevent failure.

These findings can be surprising and counterintuitive, with structural controls appearing to be less important than trust. However, this can be explained by the lack of managerial maturity on behalf of the CEO of the SME, leading to serious asymmetry of information between principal and agent during the course of the project. It appears that SMEs choose to rely on trust rather than to incur the costs of the controls needed to level out the asymmetry of information. 
In our conclusion, we cannot neglect the descriptive power of Agency Theory in a SME - OISF setting, even though the theory disregards the issue of trust. Nooteboom reaches similar results in his work on trust, opportunism and governance with the Transaction Cost Economy as an underlying theory (Nooteboom, 1996). Since the theory of Transaction Cost Economy (TCE) is also regarded as a founding theory for IS outsourcing, this may lead to suggestions for further research on TCE and trust in the same SME-OISF settings.

For researchers and practitioners, our findings also indicate that it would be more meaningful to start with a SME orientation, instead of starting with the way things are organized in large companies and thus considering only the perspective of control. The transplantation of existing IT governance mechanisms into SME soil is falling short, due to a lack of fertile theoretical foundations. Therefore, a rethinking of IT governance for SMEs is needed.

This study is subject to some limitations. Addressing a broad and relatively new research field of the governance of IT in SMEs highlights the need for more empirical evidence. Although the generalizations made in this work are of an analytical kind, the problem of external validity is recognized. Since this work is qualitative research, based on multiple case studies, we invite researchers to apply a wider variety of research methods and enlarge the external validity of the findings with quantitative techniques and surveys.

\section{References}

Adam, F. and O'Doherty, P. (2000), "Lessons from enterprise resource planning implementations in Ireland - towards smaller and shorter ERP projects", Journal of Information Technology, Vol. 15, No. 4, pp. 305-16.

Alpar, P. and Reeves, S. (1990), "Predictors of MS/OR Application in Small Businesses", Interfaces, Vol. 20, No. 2, pp. $2-11$.

Anderlini, L. and Felli, L. (2004), "Bounded rationality and incomplete contracts", Research in Economics, Vol. 58, No. 2004, pp. 3-30.

Antlova, K. (2009), "Motivation and Barriers of ICT adoption in Small and Medium-Sized Enterprises", E \& $M$ Ekonomie a Management, Vol. 12, No. 2, pp. 140-55.

Aubert, B.A., Patry, M. and Rivard, S. (2003), "A tale of two outsourcing contracts - An agency-theoretical perspective", Wirtschaftsinformatik, Vol. 45, No. 2, pp. 181-90.

Aubert, B.A., Patry, M. and Rivard, S. (2005), "A Framework for Information Technology Outsourcing Risk Management", The DATA BASE for Advances in Information Systems, Vol. 36, No. 4, pp. 9-28.

Avison, D., Gregor, S. and Wilson, D. (2006), "Managerial IT unconsciousness", Communications of the Acm, Vol. 49, No. 7, pp. 89-93.

Ballantine, J., Levy, M. and Powell, P. (1998), "Evaluating information systems in small and medium-sized enterprises: issues and evidence", European Journal of Information Systems, Vol. 7, No. 4, pp. 241-51.

Bernroider, E.W.N. (2008), "IT governance for enterprise resource planning supported by the DeLone-McLean model of information systems success", Information and Management, Vol. 45, No. 5, pp. 257-69.

Bigley, G.A. and Pearce, J.L. (1998), "Straining for shared meaning in organization science: Problems of trust and distrust", Academy of Management Review, Vol. 23, No. 3, pp. 405-21.

Blois, K.J. (1999), "Trust in business to business relationships: An evaluation of its status", Journal of Management Studies, Vol. 36, No. 2, pp. 197-215.

Blomqvist, K., Hurmelinna, P. and Seppanen, R. (2005), "Playing the collaboration game right - balancing trust and contracting", Technovation, Vol. 25, No. 5, pp. 497-504.

Chang, S.I., Hung, S.Y., Yen, D.C. and Lee, P.J. (2010), "Critical Factors of ERP Adoption for Small- and MediumSized Enterprises: An Empirical Study", Journal of Global Information Management, Vol. 18, No. 3, pp. 82106. 
Choudhury, V. and Sabherwal, R. (2003), "Portfolios of control in outsourced software development projects", Information Systems Research, Vol. 14, No. 3, pp. 291-314.

Cragg, P. (2008), "Identifying key Information Systems competencies in small firms", Total Quality Management \& Business Excellence, Vol. 19, No. 1-2, pp. 29-35.

Devos, J, Van Landeghem, H \& Deschoolmeester, D 2010, 'The Theory of the Lemon Markets in IS research', in YK Dwivedi, M Wade \& SL Schneberger (eds), Information Systems Theory: Explaining and Predicting Our Digital Society, Springer.

Dibbern, J., Goles, T. and Hirschheim, R. (2004), "Information Systems Outsourcing: A Survey and Analysis of the Literature", The DATA BASE for Advances in Information Systems, Vol. 35, No. 4, pp. 6-102.

Dube, L. and Pare, G. (2003), "Rigor in information systems positivist case research: Current practices, trends, and recommendations", Mis Quarterly, Vol. 27, No. 4, pp. 597-635.

Eisenhardt, K.M. (1989a), "Agency Theory: An Assessment and Review", Academy of Management Review, Vol. 14, No. 1, pp. 57-74.

Eisenhardt, K.M. (1989b), 'Building Theories from Case-Study Research", Academy of Management Review, Vol. 14, No. 4 , pp. 532-50.

European Commission, (2003), "Commission Recommendation 2003/361/EC", Official Journal of the European Union, Vol. 46, No. L 124, p. 6.

Ewusi-Mensah, K. (2003), Software Development Failures, MIT Press, Cambridge.

Gefen, D. (2004), "What makes an ERP implementation relationship worthwhile: Linking trust mechanisms and ERP usefulness", Journal of Management Information Systems, Vol. 21, No. 1, pp. 263-88.

Grossman, S.J. and Hart, O.D. (1983), "An Analysis of the Principal-Agent Problem", Econometrica, Vol. 51, No. 1, pp. $7-45$.

Harrison, D.A., Mykytyn, P.P. and Riemenschneider, C.K. (1997), "Executive decisions about adoption of information technology in small business: Theory and empirical tests", Information Systems Research, Vol. 8, No. 2, pp. 171-95.

Huang, R., Zmud, R.W. and Price, R.L. (2010), "Influencing the effectiveness of IT governance practices through steering committees and communication policies", European Journal of Information Systems, Vol. 19, No. 3, pp. 288-302.

Iacovou, C.L. and Dexter, A. (2005), "Surviving IT project cancellations", Communications of the Acm, Vol. 48, No. 4, pp. 83-86.

IT Governance Institute, (2007), Cobit Quickstart 2th Edition, IT Governance Institute.

Jensen, M.C. and Meckling, W.H. (1976), "Theory of the Firm - Managerial Behavior, Agency Costs and Ownership Structure", Journal of Financial Economics, Vol. 3, No. 4, pp. 305-60.

Kirsch, L.J. (1997), "Portfolios of control modes and IS project management", Information Systems Research, Vol. 8, No. 3, pp. 215-39.

Lander, M.C., Purvis, R.L., McCray, G.E. and Leigh, W. (2004), "Trust-building mechanisms utilized in outsourced IS development projects: a case study", Information \& Management, Vol. 41, No. 4, pp. 509-528.

Lee, A.S. (1989), "A Scientific Methodology for MIS Case Studies", Mis Quarterly, Vol. 13, No. 1, pp. 33-50.

Lee, A.S. and Baskerville, R.L. (2003), "Generalizing generalizability in information systems research", Information Systems Research, Vol. 14, No. 3, pp. 221-243.

Lefebvre, L.A., Mason, R. and Lefebvre, E. (1997), "The influence prism in SMEs: The power of CEOs' perceptions on technology policy and its organizational impacts", Management Science, Vol. 43, No. 6, pp. 856-878.

Levy, M. and Powell, P. (2008), "Small firm transformation through IS", International Journal of Technology Management, Vol. 43, No. 1-3, pp. 123-141. 
Lyytinen, K. and Hirschheim, R. (1987),"'Information Systems Failures - A Survey and Classification of the Empirical Literature", Oxford Surveys in Information Technology, Vol. 4, pp. 257-309.

Markus, M.L. and Robey, D. (1988), "Information Technology and Organizational Change - Causal Structure in Theory and Research", Management Science, Vol. 34, No. 5, pp. 583-98.

Mohtashami, M., Marlowe, T., Kirova, V. and Deek, F.P. (2006), "Risk management for collaborative software development", Information Systems Management, Vol. 23, No. 4, pp. 20-30.

Moynihan, T. (2002), "Coping with client-based 'people-problems': the theories-of-action of experienced IS/software project managers", Information \& Management, Vol. 39, No. 5, pp. 377-90.

Natovich, J. (2003), "Vendor related risks in IT development: A chronology of an outsourced project failure", Technology Analysis \& Strategic Management, Vol. 15, No. 4, pp. 409-19.

Nooteboom, B. (1996), "Trust, opportunism and governance: A process and control model", Organization Studies, Vol. 17, No. 6, pp. $985-1010$.

Premkumar, G. (2003), "A meta-analysis of research on information technology implementation in small business", Journal of Organizational Computing and Electronic Commerce, Vol. 13, No. 2, pp. 91-121.

Raymond, L. (1985), "Organizational Characteristics and MIS Success in the Context of Small Business", Mis Quarterly, Vol. 9, No. 1, pp. 37-52.

Reed, M.I. (2001), "Organization, trust and control: A realist analysis', Organization Studies", Vol. 22, No. 2, pp. 201-28.

Riemenschneider, C.K., Harrison, D.A. and Mykytyn, P.P. (2003), "Understanding it adoption decisions in small business: integrating current theories", Information \& Management, Vol. 40, No. 4, pp. 269-85.

Sabherwal, R. (1999), "The role of trust in outsourced IS development projects", Communications of the Acm, Vol. 42, No. 2, pp. 80-86.

Sarker, S. and Lee, A.S. (2003), "Using a case study to test the role of three key social enablers in ERP implementation", Information \& Management, Vol. 40, No. 8, pp. 813-29.

Sauer, C. (1993), Why Information Systems Fail: A Case Study Approach, Alfred Wailer, Henley-on-Thames.

Schmidt, R, Lyytinen, K, Keil, M \& Cule, P 2001, 'Identifying software project risks: An international Delphi study', Journal of Management Information Systems, vol. 17, no. 4, pp. 5-36.

Schwarz, A. and Hirschheim, R. (2003), "An extended platform logic perspective of IT governance: managing perceptions and activities of IT", Journal of Strategic Information Systems, Vol. 12, No. 2, pp. 129-66.

Soh, C. and Markus, M.L. (1995), "How IT creates business value: a process theory synthesis", paper presented on the $16^{\text {th }}$ ICIS conference, 1995 , Amsterdam

Standish Group, (2004), Third Quarter Research Report, The Standish Group International.

Thong, J.Y.L., Yap, C.S. and Raman, K.S. (1997), "Environments for Information Systems Implementation in Small Businesses", Journal of Organizational Computing and Electronic Commerce, Vol. 7, No. 4, pp. 253-78.

Thong, J.Y.L. (2001), "Resource constraints and information systems implementation in Singaporean small businesses", Omega-International Journal of Management Science, Vol. 29, No. 2, pp. 143-56.

Weill, P. and Ross, J. (2004), IT Governance: How Top Performers Manage IT Decision Rights for Superior Results, Harvard Business Press.

Weill, P. and Ross, J. (2005), "A matrixed approach to designing IT governance", Mit Sloan Management Review, Vol. 46, No. 2, pp. 26-34.

Yin, R.K. (2003), Case Study Research: Design and Methods, Third Edition edn, Vol. 5, 31 vols., Applied Social Research Methods Series, Sage Publications, Inc, Thousand Oaks, London, New Delhi.

Zaheer, A., McEvily, B. and Perrone, V. (1998), "Does trust matter? Exploring the effects of interorganizational and interpersonal trust on performance", Organization Science, Vol. 9, No. 2, pp. 141-59. 
